\title{
The influence of hemodilution on outcome after hypothermic cardiopulmonary bypass: Results of a randomized trial in infants
}

\author{
Richard A. Jonas, MD ${ }^{a, g}$ \\ David Wypij, PhD ${ }^{\mathrm{b}, \mathrm{f}, \mathrm{k}}$ \\ Stephen J. Roth, MD, MPH \\ David C. Bellinger, $\mathrm{PhD}, \mathrm{MSc}^{\mathrm{c}, \mathrm{j}}$ \\ Karen J. Visconti, $\mathrm{PhD}^{\mathrm{a}}$ \\ Adre J. du Plessis, MBChB, MPH ${ }^{\mathrm{c}, \mathrm{j}}$ \\ Howard Goodkin, MD ${ }^{\mathrm{c}, \mathrm{j}}$ \\ Peter C. Laussen, $M D^{d, i}$ \\ David M. Farrell, MACCPa \\ Jodi Bartlett, $\mathrm{RN}^{\dagger}$ \\ Ellen McGrath, $\mathrm{RN}^{\mathrm{f}}$ \\ Leonard J. Rappaport, MD ${ }^{\mathrm{e}, \mathrm{h}}$ \\ Emile A. Bacha, MD ${ }^{\mathrm{a}, \mathrm{g}}$ \\ Joseph M. Forbess, MD $D^{a, g}$ \\ Pedro J. del Nido, $M^{a, g}$ \\ John E. Mayer, Jr, MD ${ }^{a, g}$ \\ Jane W. Newburger, MD, MPH ${ }^{\mathrm{b}, \mathrm{h}}$
}

From the Departments of Cardiovascular Surgery, ${ }^{\mathrm{a}}$ Cardiology, ${ }^{\mathrm{b}}$ Neurology, ${ }^{\mathrm{c}}$ Anesthesia, ${ }^{\mathrm{d}}$ and Pediatrics, ${ }^{\mathrm{e}}$ and the Clinical Research Program, ${ }^{f}$ Children's Hospital Boston, Boston, Mass; the Departments of Surgery, ${ }^{\mathrm{g}}$ Pediatrics, ${ }^{\mathrm{h}}$ Anesthesia,${ }^{\mathrm{i}}$ and Neurology, ${ }^{\mathrm{j}}$ Harvard Medical School, Boston, Mass; and the Department of Biostatistics, ${ }^{\mathrm{k}}$ Harvard School of Public Health, Boston, Mass.

Supported by grants HL 063411 and RR 02172 from the National Institutes of Health.

Read at the Eighty-second Annual Meeting of The American Association for Thoracic Surgery, Washington, DC, May 5-8, 2002.

Received for publication Oct 28, 2002; revisions requested Jan 21, 2003; revisions received March 3, 2003; accepted for publication April 11, 2003

Address for reprints: Richard A. Jonas, MD, Department of Cardiovascular Surgery, Children's Hospital Boston, 300 Longwood Ave, Boston, MA 02115 (Email: Richard.Jonas@tch.harvard.edu).

J Thorac Cardiovasc Surg 2003;126: 1765-74

Copyright () 2003 by The American Association for Thoracic Surgery

$0022-5223 / 2003 \$ 30.00+0$

doi:10.1016/j.jtcvs.2003.04.003
Background: We hypothesized that cognitive impairment and hemodynamic instability after infant cardiac surgery with cardiopulmonary bypass might be exacerbated by hemodilution.

Methods: In a single-center randomized trial with blinded assessment of outcomes, we compared use of 2 hemodilution protocols during hypothermic cardiopulmonary bypass with infant cardiac surgery. The primary perioperative end point was lowest cardiac index in the first 24 hours postoperatively, and primary end points at age 1 year were scores on the Psychomotor Development Index and Mental Developmental Index of the Bayley Scales.

Results: Among 147 subjects, 74 were assigned to the lower-hematocrit strategy $(21.5 \% \pm 2.9 \%$, mean $\pm \mathrm{SD}$ at onset of low-flow bypass) and 73 to the higherhematocrit strategy $(27.8 \% \pm 3.2 \%)$. In intent-to-treat analyses the lower-hematocrit group had lower nadirs of cardiac index $(P=.02)$, higher serum lactate levels 60 minutes after cardiopulmonary bypass $(P=.03)$, and a greater percentage increase in total body water on the first postoperative day $(P=.006)$. Blood product use and adverse events were similar in the 2 groups. At age 1 year (113 children), the lower-hematocrit group had worse scores on the Psychomotor Development Index $(81.9 \pm 15.7$ vs $89.7 \pm 14.7, P=.008)$, as well as more Psychomotor Development Index scores at least 2 SDs below the population mean (16/56 [29\%] vs $5 / 53$ [9\%], $P=.01$ ). The groups had similar Mental Developmental Index scores and findings on neurologic examination. Inferences using hematocrit as a continuous variable were similar to those based on intent-to-treat analyses.

Conclusions: Hemodilution to a hematocrit level in wide use for cardiopulmonary bypass and thought to be safe is associated with adverse perioperative and developmental outcomes in infants. 


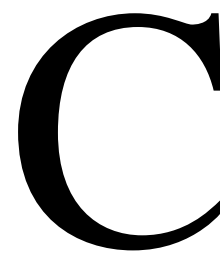

ognitive impairment has been observed consistently in adults after cardiopulmonary bypass $(\mathrm{CPB})^{1}$ and is associated with the number of microemboli detected during coronary artery bypass grafting. ${ }^{2}$ However, children, who are generally free of atherosclerosis, also can have neurocognitive sequelae after CPB. In animal models magnetic resonance and near-infrared spectroscopy suggest that brain injury might be caused by hypoxic-ischemic injury as a result of currently recommended protocols for hemodilution during $\mathrm{CPB} .^{3}$

Hemodilution during CPB was introduced in the 1950s to decrease homologous blood use $\mathrm{e}^{4}$ and has been thought to improve microcirculatory flow. ${ }^{5}$ However, hemodilution also might reduce perfusion pressure, which increases the risk of an adverse neurologic outcome after CPB. ${ }^{6}$ Furthermore, hemodilution increases cerebral blood flow ${ }^{7}$ and thereby might increase the microembolic load to the brain. Finally, hemodilution reduces the oxygen carrying capacity of blood; in combination with the leftward shift of oxyhemoglobin dissociation induced by hypothermia, which might be further exacerbated by use of an alkaline $\mathrm{pH}$ strategy, hemodilution might critically limit oxygen delivery to neurons and other cells.

Although experience with cardiovascular surgery in adults refusing transfusion suggests that very low hematocrit levels can be tolerated, ${ }^{8}$ the optimal hematocrit level for cerebral protection during hypothermic CPB has not been defined. Published expert opinion ${ }^{9}$ has suggested that hematocrit levels of greater than $15 \%$ to $20 \%$ are safe during CPB in adults, but no randomized trials in either adults or children have examined the influence of hemodilution during $\mathrm{CPB}$ on cognitive outcomes.

We hypothesized that greater hemodilution during hypothermic CPB is associated with an increased risk of developmental impairment. To evaluate this hypothesis, we conducted a prospective, randomized, single-center trial in infants less than 9 months of age undergoing reparative cardiac surgery with CPB. We compared hemodilution with a hematocrit level of approximately $20 \%$ versus $30 \%$ with respect to outcomes measured in the early postoperative period and at age 1 year.

\section{Methods}

\section{Enrollment of Patients}

We enrolled patients between November 1996 and November 2000 at Children's Hospital Boston. Eligibility criteria included reparative cardiac surgery at less than 9 months of age for diagnoses including D-transposition of the great arteries (D-TGA) with intact ventricular septum or ventricular septal defect (VSD), tetralogy of Fallot (TOF), TOF with pulmonary atresia, truncus arteriosus, VSD, or complete common atrioventricular canal defect. Exclusion criteria included birth weight of less than $2.3 \mathrm{~kg}$, recognizable syndrome of congenital anomalies, associated extra- cardiac anomalies of greater than minor severity (defined as those that do not require treatment and have no effect on functional status), previous cardiac surgery, or associated cardiovascular anomalies requiring aortic arch reconstruction or additional open surgical procedures before the planned developmental follow-up.

Of 209 eligible infants for whom informed consent was requested, participation was declined in 57 (27\%) cases. Of the 152 patients enrolled, 5 (3\%) were excluded post hoc because the operation was not performed as planned or because the patient was discovered to have been ineligible after further clinical information was obtained. The remaining 147 patients underwent reparative surgical intervention according to the study protocol and constitute the study population. Parental informed consent was obtained according to institutional guidelines.

\section{Study Design}

Participating infants were randomly assigned to undergo hemodilution to a hematocrit level of approximately $20 \%$ versus $30 \%$, with stratification according to surgeon and diagnostic group by using blocked randomization. The method of support was assigned immediately before the operation. Treatment assignment was directly observed by the perfusionists and study nurses. These individuals did not have access to interim study results. The surgeons, anesthesiologists, cardiac intensivists, neurologists, and developmental psychologists were blinded to patient treatment assignment.

\section{Anesthesia and Perfusion Methods}

After induction of anesthesia and placement of an arterial catheter, surface cooling was begun with a low ambient room temperature, a cooling mattress, and ice packs to the head. CPB and core cooling were begun as soon as the venous and aortic cannulae were in place. Patients had variable periods of fullflow CPB at approximately $2.5 \mathrm{~L} \cdot \min ^{-1} \cdot \mathrm{m}^{-2}$ when cooling to various levels of hypothermia and usually during rewarming. Some patients had periods of deep hypothermic circulatory arrest, and most had at least one period of reduced-flow CPB (eg, at approximately $0.75 \mathrm{~L} \cdot \mathrm{min}^{-1} \cdot \mathrm{m}^{-2}$ when at deep hypothermia [ie, rectal temperature of $\left.<18^{\circ} \mathrm{C}\right]$ ). After patient randomization, hemodilution was achieved with whole blood and PlasmaLyte A pH 7.4 (Baxter Healthcare Corp, Deerfield, III). Standard perfusion calculations were used to determine the volumes of the priming constituents, with the aim of obtaining a hematocrit level of $20 \%$ or $30 \%$ at the time of onset of low-flow CPB. Five patients did not have a period of low-flow bypass. In intent-to-treat analyses these patients were included in the group to which they were randomized; for continuous analyses, we used the hematocrit level at the onset of rewarming. Hypothermic myocardial protection was provided by means of infusion of oxygenated crystalloid cardioplegia (Plegisol; Abbott Laboratories, North Chicago, Ill) usually as a single dose of $20 \mathrm{~mL} / \mathrm{kg}$ or a custom mix of 4 parts crystalloid to 1 part blood (Baxter Compass, Edison, NJ). The pH-stat strategy was used during core cooling, low-flow hypothermic perfusion, and rewarming up to $30^{\circ} \mathrm{C}$. Anesthetic management and other aspects of perfusion on $\mathrm{CPB}$ were identical for both groups. We used conventional ultrafiltration during $\mathrm{CPB}$ but not modified ultrafiltration after $\mathrm{CPB}$. 


\section{Early Postoperative Data}

During the first 24 hours after the operation, cardiac output was determined at 3-hour intervals after removal of the aortic crossclamp by using the thermodilution technique. We measured serum lactate 60 minutes after $\mathrm{CPB}$. At 8 AM each day in the intensive care unit, the study nurses recorded data on events, medications, respiratory status, laboratory studies, fluid inputs and outputs, and blood and blood product requirements. Bioelectric impedance was measured preoperatively and on the first postoperative day to estimate total body water.

\section{Neurologic Examination}

Neurologic examination was performed by pediatric neurologists according to a uniform and predetermined protocol before the operation and again at age 1 year. Abnormalities on neurologic examination were classified according to specific type, including head circumference, mental status, special senses, cranial nerve motor function, and peripheral motor function. Patients were classified as having an abnormal neurologic examination result if any summary item included a definite abnormality.

\section{Developmental Evaluation}

Of the 146 children alive at age 1 year, 20 were not invited to return because of residence outside the United States $(n=12)$, parental inability to speak English $(n=3)$, older age by the time travel funds were procured $(n=4)$, and diagnosis of chromosome 18 abnormality ascertained after the operation $(n=1)$. Of the remaining 126 families, 4 (3\%) declined participation, 3 (2\%) were lost to follow-up, $2(2 \%)$ cancelled their travel after the terrorist attacks of September 11, 2001, and 4 (3\%) declined in-person evaluation but completed questionnaires. The remaining 113 (90\%) children returned for in-person evaluation. One child was tested only with a neurologic examination. Information on family characteristics was obtained from interviews with the parents.

Two examiners administered the Bayley Scales of Infant Development, ${ }^{10}$ which yield scores on 2 indexes: the Psychomotor Development Index (PDI) and the Mental Development Index (MDI). We also calculated the proportion of children whose scores were 85 or less or 70 or less (at least 1 or 2 SDs below the population mean, respectively).

\section{Statistical Analyses}

The treatment groups were compared in intent-to-treat analyses. Secondary analyses examined the effect of hematocrit level at the onset of low-flow CPB as a continuous variable. All tests of hypotheses and regression analyses of outcome variables were adjusted for diagnostic group and grouped in the following way: D-TGA (D-TGA/intact ventricular septum and D-TGA/VSD); TOF (TOF, TOF with pulmonary atresia, and truncus arteriosus); and VSD (VSD or common atrioventricular canal defect). We also assessed potential interactions between hemodilution (treatment assignment or hematocrit level as a continuous variable) and diagnostic group on outcomes. On the basis of previous work, the nadir of the cardiac index was the primary outcome variable in the perioperative period. PDI and MDI scores were the primary outcomes at age 1 year.

Outcomes included both continuous and categoric variables. Linear regression and exact stratified Wilcoxon tests were used to analyze continuous variables. Stratified exact tests and logistic regression methods were used to analyze categoric variables. In addition to diagnostic group, we performed analyses assessing whether other potential predictor variables confounded or modified the effects of hemodilution on primary and secondary end points. These predictor variables included surgeon, sex, age at the time of the operation, interval between the operation and developmental examination, birth weight, maternal education, paternal education, family social class, gestational age, Apgar score of 1, Apgar score of 5, preoperative intubation, preoperative acidosis, calendar date of the operation, preoperative neurologic examination results, type of cardioplegia solution, lowest tympanic temperature, duration of circulatory arrest, total bypass time, total support time, and individual performing developmental testing. All $P$ values are 2 -tailed.

Assuming a sample size of 60 in each treatment group returning for follow-up at age 1 year, our study had a power of $85 \%$ to detect differences between treatment groups of 9 points (0.6 SD units) after adjustment for simultaneous testing of the 2 primary outcomes (PDI and MDI scores) at age 1 year by using the Bonferroni method. Our National Heart, Lung, and Blood Institute-appointed Data and Safety Monitoring Board terminated the study when 147 patients had been enrolled and 78 had returned for follow-up at age 1 year. At that time, statistical significance for early stopping was reached with sequential analysis methods by using O'Brien-Fleming stopping rules without multiple comparison adjustment and Pocock stopping rules with or without multiple comparison adjustment. The O'Brien-Fleming stopping rules with multiple comparison adjustment did not quite reach statistical significance. In considering all of the data, including differences between treatment groups in postoperative outcomes, the Data and Safety Monitoring Board stopped patient enrollment on December 2, 2000.

\section{Results}

\section{Comparability of Treatment Groups}

Among the 147 infants enrolled, 74 were assigned to the lower-hematocrit group and 73 to the higher-hematocrit group (Table 1). Treatment assignments were balanced within the randomization strata of diagnostic group and surgeon. The randomized infants within each diagnostic group were similar at enrollment with regard to preoperative variables that might influence outcomes, including preoperative neurologic assessment.

\section{Intraoperative Data}

In accordance with the randomized assignments, the treatment groups differed significantly with regard to hematocrit level at the onset of low-flow CPB and at several other intraoperative perfusion phases (Figure 1) but were similar in durations of total CPB, circulatory arrest, low-flow bypass, total support (ie, total CPB time plus circulatory arrest time), crossclamping, rates of cooling and rewarming, and $\mathrm{pH}$ and $\mathrm{CO}_{2}$ levels before and during $\mathrm{CPB}$ (Table 1). The proportion of subjects receiving each type of cardioplegia (ie, Plegisol or the custom mix) was similar between treatment groups; Plegisol was used in 18 (24\%) of 74 and 16 (22\%) of 73 subjects randomized to the lower- and higher- 
TABLE 1. Perioperative and operative characteristics according to treatment group

\begin{tabular}{|c|c|c|}
\hline & $\begin{array}{c}\text { Lower hematocrit } \\
\text { level }(n=74) \\
\text { mean } \pm \text { SD }\end{array}$ & $\begin{array}{c}\text { Higher hematocrit } \\
\text { level }(\mathrm{n}=73) \\
\text { mean } \pm \text { SD }\end{array}$ \\
\hline \multicolumn{3}{|l|}{ Preoperative characteristics } \\
\hline Birth weight $(\mathrm{kg})$ & $3.37 \pm .59$ & $3.40 \pm .61$ \\
\hline Gestational age (wk) & $39.0 \pm 1.5$ & $39.0 \pm 1.7$ \\
\hline Apgar score at $5 \mathrm{~min}$ & $8.6 \pm 1.0$ & $8.5 \pm 0.8$ \\
\hline $\begin{array}{l}\text { Age at operation, median } \\
\text { (range) }\end{array}$ & $33(1-259)$ & $45(1-269)$ \\
\hline Sex $(\%$ male $)$ & 61 & 71 \\
\hline Race (\% nonwhite) & 23 & 16 \\
\hline \multicolumn{3}{|l|}{ Diagnosis group, $\mathrm{n}(\%)$} \\
\hline D-TGA & $29(39)$ & $29(40)$ \\
\hline TOF/other & $24(32)$ & $23(32)$ \\
\hline VSD/CAVC & $21(28)$ & $21(29)$ \\
\hline Ever intubated (\%) & 46 & 36 \\
\hline $\begin{array}{l}\text { Intubated at operation } \\
(\%)\end{array}$ & 23 & 22 \\
\hline \multicolumn{3}{|l|}{ Operative characteristics } \\
\hline $\begin{array}{l}\text { Hematocrit level at onset } \\
\text { of low-flow bypass }\end{array}$ & $21.5 \pm 2.9$ & $27.8 \pm 3.2^{*}$ \\
\hline Crossclamp time & $64 \pm 23$ & $64 \pm 25$ \\
\hline Total support time (min) & $107 \pm 32$ & $110 \pm 38$ \\
\hline Total bypass time (min) & $99 \pm 30$ & $104 \pm 34$ \\
\hline Low-flow bypass (min) & $40 \pm 23$ & $46 \pm 26$ \\
\hline $\begin{array}{l}\text { Duration of circulatory } \\
\text { arrest (min), median } \\
\text { (range) }\end{array}$ & $0(0-53)$ & $0(0-58)$ \\
\hline None, n (\%) & $40(54)$ & $45(62)$ \\
\hline $1-10$ & $18(24)$ & $20(27)$ \\
\hline $11-30$ & $10(14)$ & $3(4)$ \\
\hline $31-44$ & $3(4)$ & $3(4)$ \\
\hline$\geq 45$ & $3(4)$ & $2(3)$ \\
\hline $\begin{array}{l}\text { Fluid balance (mL), (in } \\
\text { minus out) }\end{array}$ & $519 \pm 343$ & $337 \pm 222 \dagger$ \\
\hline $\begin{array}{l}\text { Intraoperative blood } \\
\text { products (mL), median } \\
\text { (range) }\end{array}$ & $168(25-1383)$ & $165(30-480)$ \\
\hline \multicolumn{3}{|l|}{$\begin{array}{l}\text { Preoperative neurologic } \\
\text { examination }\end{array}$} \\
\hline $\begin{array}{l}\text { Overall evaluation (\% } \\
\text { abnormal) }\end{array}$ & 65 & 68 \\
\hline
\end{tabular}

CAVC, Common atrioventricular canal defect.

${ }^{*} P<.001$ for difference between treatment groups determined by means of linear regression, with adjustment for diagnosis group.

$\dagger P=.001$ for difference between treatment groups determined by means of linear regression, with adjustment for diagnosis group.

hematocrit strategies, respectively. Intraoperative blood product use was similar between groups.

\section{Postoperative Course}

One $(0.7 \%)$ infant randomized to the lower-hematocrit group died within 1 month of the operation. Infants in the lower-hematocrit group compared with those in the higherhematocrit group had lower nadirs of cardiac index over the

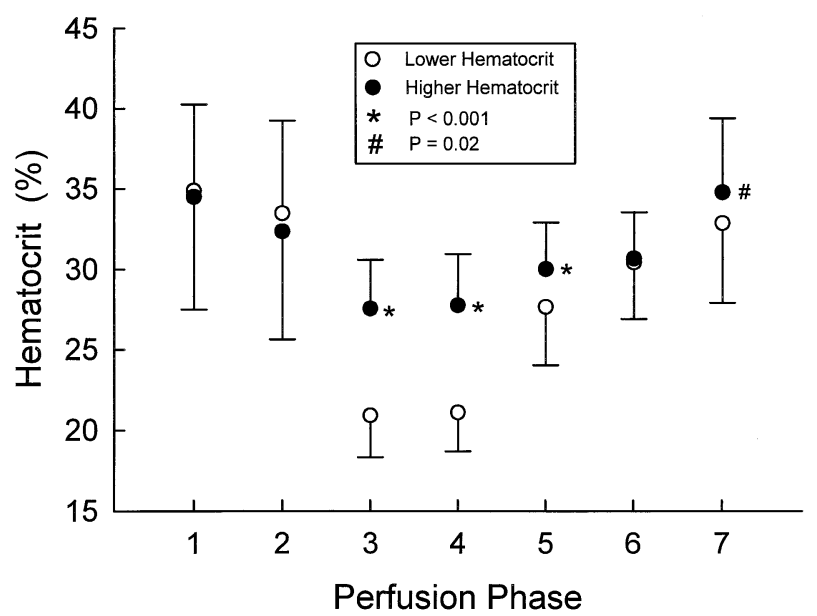

Figure 1. Plot of serial measurements of hematocrit levels according to perfusion phases defined as follows: 1 , after induction of anesthesia; 2, administration of heparin; 3, 10 minutes after onset of cooling; 4, onset of low-flow bypass; 5,10 minutes after onset of rewarming; 6, start of warm flow; and 7,60 minutes off bypass. Values are depicted as the mean \pm 1 SD. After adjustment for diagnostic group, statistically significant differences were found for phases $3,4,5$, and 7 .

first postoperative 24 hours $(2.8 \pm 1.1$ vs. $3.1 \pm 1.1 \mathrm{~L}$. $\left.\min ^{-1} \cdot \mathrm{m}^{-2}, P=.02\right)$, as well as significantly lower cardiac indexes at 6,9 , and 24 hours after removal of the aortic crossclamp (Figure 2). Inotropic administration was greater in the lower-hematocrit group at each 3-hour interval, although the magnitude of the difference between groups did not reach statistical significance at any of these time points. The lower-hematocrit group also had higher serum lactate levels 60 minutes after cessation of CPB (3.3 \pm 1.9 vs $2.7 \pm 1.3 \mathrm{mmol} / \mathrm{L}, P=.03)$, as well as greater percentage decreases in bioelectric impedance from the preoperative period to the first postoperative day $(-38.2 \%$ $\pm 16.5 \%$ vs $-28.4 \% \pm 20.3 \%, P=.006$ ), reflecting a greater percentage increase in total body water. In models examining the effect of hematocrit level as a continuous variable on perioperative outcomes, inferences were similar to those based on the intent-to-treat analyses. Differences between the hemodilution groups in durations of tracheal intubation or time until hospital discharge did not reach statistical significance (Table 2). Similarly, the incidence of adverse events and the use of blood and blood products were similar in the groups. No infant in either group had definite clinical seizures.

\section{Developmental Testing at Age 1 Year}

The proportion of children in each treatment group who returned for developmental follow-up was similar. Those who returned for evaluation compared with those who did not had parents with significantly higher educational levels 


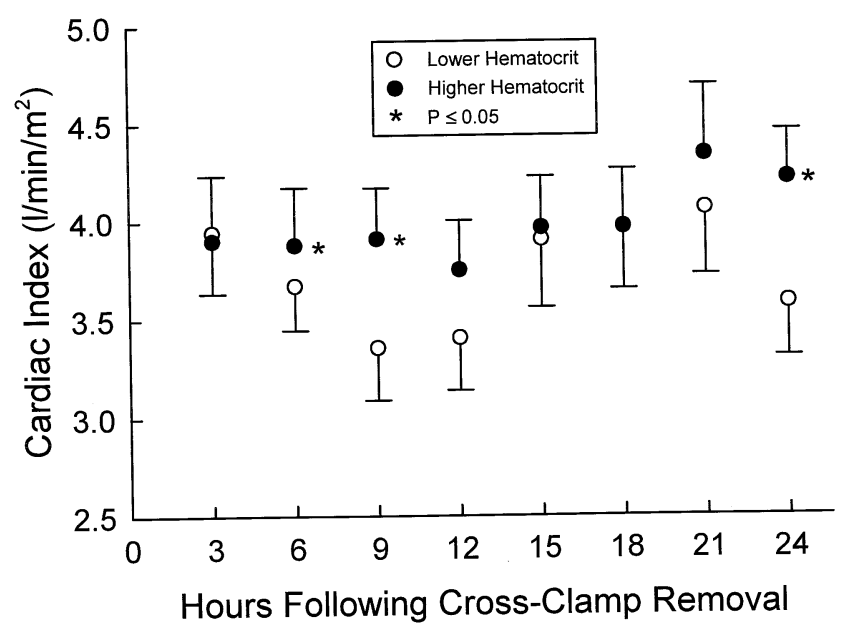

Figure 2. Plot of serial measurements of cardiac index, as determined by using the thermodilution technique. Values are depicted as the mean $\pm 1 \mathrm{SD}$. Not all patients had measurements in all time periods; however, only those with measurements in at least 4 time periods were included in analyses. After adjustment for diagnostic group, statistically significant differences were found at 6,9 , and 24 hours after removal of the aortic crossclamp.

and were more likely to be white but were otherwise similar in perioperative characteristics. No subjects underwent cardiac reoperation before returning for developmental testing.

In 113 children returning at age 1 year, the lower-hematocrit group had worse PDI scores $(81.9 \pm 15.7$ vs $89.7 \pm$ $14.7, P=.008$; Figure 3 ) and more PDI scores at least 2 SDs less than the population mean (16/56 [29\%] vs 5/53 [9\%], $P=.01$; Table 3). After stepwise linear regression modeling, adjusting for diagnostic group, higher PDI scores were related to the absence of preoperative endotracheal intubation $(P=.03)$, higher birth weight $(P=.03)$, lower social class $(P=.01)$, and assignment to the higher-hematocrit group $(P<.01)$. Among these factors, hematocrit treatment assignment was the single most important predictor of PDI scores in terms of statistical significance and improvement in proportion of variance explained $(6.3 \%)$. When hematocrit level at the onset of low-flow CPB was analyzed as a continuous variable, adjusting for diagnostic group, lower hematocrit levels were associated with lower PDI scores $(P=.02$, adjusting for diagnostic group; Figure 4). A change in hematocrit level from $20 \%$ to $30 \%$ was associated with an 8.2-point increase in PDI score, greater than a half SD difference. After further adjustment in stepwise linear regression for preoperative endotracheal intubation, birth weight, and social class, hematocrit level at the onset of low-flow bypass remained a significant predictor of PDI score $(P=.03)$.

Mean scores on the MDI were similar in the lower- and higher-hematocrit groups $(92.1 \pm 14.5$ vs $94.4 \pm 11.0$,
TABLE 2. Postoperative course according to treatment group $P$ value*

\begin{tabular}{|c|c|c|c|}
\hline Variable & $\begin{array}{c}\text { Lower hematocrit } \\
\text { level }(n=74)\end{array}$ & $\begin{array}{l}\text { Higher hematocrit } \\
\text { level }(\mathrm{n}=73)\end{array}$ & $\begin{array}{c}P \\
\text { value* }^{*}\end{array}$ \\
\hline $\begin{array}{l}\text { Lowest cardiac } \\
\text { index }\left(\mathrm{L} \cdot \mathrm{min}^{-1} \text {. }\right. \\
\left.\mathrm{m}^{-2}\right)\end{array}$ & $2.8 \pm 1.1$ & $3.1 \pm 1.1$ & .02 \\
\hline $\begin{array}{l}\text { Lactate } 60 \text { min after } \\
\text { bypass }\end{array}$ & $3.3 \pm 1.9$ & $2.7 \pm 1.3$ & .03 \\
\hline $\begin{array}{l}\text { Resistance }(\% \\
\text { change from } \\
\text { preoperative to } \\
\text { postoperative day } \\
\text { 1) }\end{array}$ & $-38.2 \pm 16.5$ & $-28.4 \pm 20.3$ & .006 \\
\hline $\begin{array}{l}\text { Postoperative blood } \\
\text { products (total) } \\
\text { (mL), median } \\
\text { (range) }\end{array}$ & $126(0,3551)$ & $120(0,1874)$ & .58 \\
\hline $\begin{array}{l}\text { Days intubated, } \\
\text { median } \\
\text { (interquartile } \\
\text { range) }\end{array}$ & $1.9(1.0,2.9)$ & $1.5(1.1,2.8)$ & $.35 \dagger$ \\
\hline $\begin{array}{l}\text { Days in ICU, } \\
\text { median } \\
\text { (interquartile } \\
\text { range) }\end{array}$ & $4(2-5)$ & $3(2-4)$ & $.15 \dagger$ \\
\hline $\begin{array}{l}\text { Days in hospital, } \\
\text { median } \\
\text { (interquartile } \\
\text { range) }\end{array}$ & $7(5-9)$ & $6(5-9)$ & $.39 \dagger$ \\
\hline
\end{tabular}

ICU, Intensive care unit.

${ }^{*} P$ values determined by means of linear regression, are for differences between treatment groups, with adjustment for diagnosis group.

$\dagger P$ values determined by means of Wilcoxon rank sum tests, are for differences between treatment groups, with adjustment for diagnosis group.

respectively; Figure 3). A greater proportion of children in the lower-hematocrit group compared with the higher-hematocrit group had MDI scores more than 1 SD less than the mean $(18 / 59$ [31\%] vs $6 / 53$ [11\%], $P=.02)$. The treatment groups did not differ significantly in the percentage of children with MDI scores more than 2 SDs less than the mean, but our power to detect differences was extremely limited. Significant predictors of higher MDI scores included female sex $(P=.02)$, higher birth weight $(P=.007)$, and higher social class $(P=.005)$. In multiple regression models hematocrit levels at the onset of low-flow CPB were not significantly associated with MDI scores.

Abnormal neurologic examination results were common but did not differ in frequency between the lower- and higher-hematocrit groups (60\% vs 58\%, respectively). Similarly, no treatment group differences were found with respect to specific types of abnormalities (Table 4). Common findings in both groups were abnormal muscle tone (usually decreased) and abnormal oromotor function. 


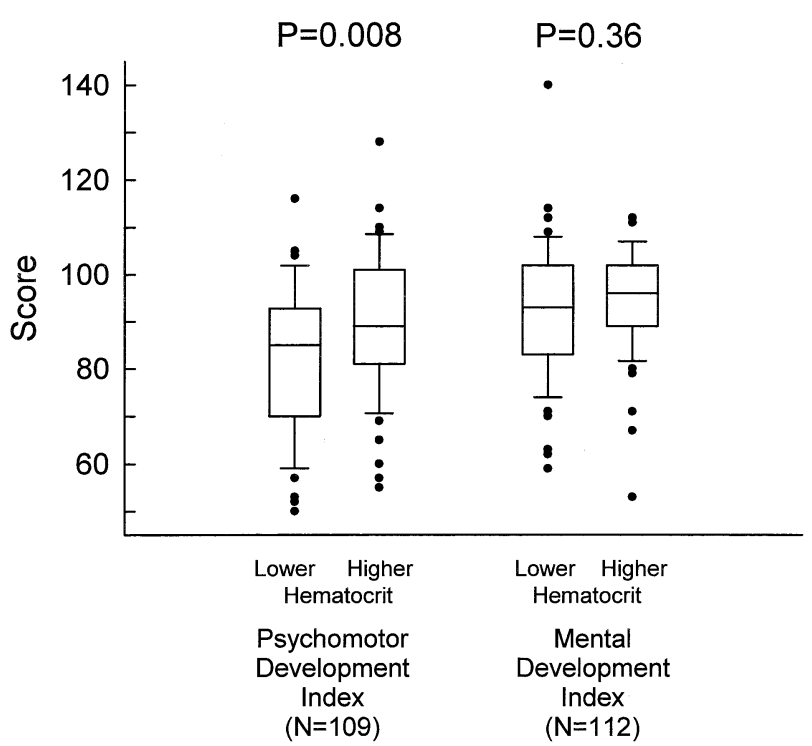

Figure 3. Box plots of PDI and MDI scores at age 1 year according to hematocrit group (lower hematocrit level vs higher hematocrit level at the onset of low-flow bypass). The solid bar within the box represents the median value, the upper boundary of the box represents the 75th percentile, and the lower boundary of the box represents the 25th percentile. The vertical lines extend to the 10th and 90th percentiles, with more extreme observations plotted as circles. The linear regression $P$ values shown are for the effect of hematocrit group on outcome, with adjustment for diagnostic group.

\section{Influence of Other Surgical Variables}

We explored whether the effect of hematocrit strategy on study outcome was influenced by perfusion variables, including type of cardioplegia, use and duration of total circulatory arrest, duration of low-flow bypass, or degree of hypothermia. There was a significant interaction between treatment assignment and type of cardioplegia for nadir of cardiac index $(P=.01)$ and percentage change in bioimpedance on postoperative day $1(P=.03)$, with treatment group differences being slightly larger among those who received Plegisol. However, with either cardioplegia solution, assignment to the higher-hematocrit strategy provided better outcomes. There was no significant interaction between treatment assignment and type of cardioplegia with respect to lactate level 60 minutes after cessation of bypass, PDI score, or MDI score. Similarly, we found no significant interaction between either treatment assignment or hematocrit level as a continuous variable and the other perfusion variables in their effects on early postoperative outcomes or outcomes at age 1 year. In addition, adjustment for surgeon or a surgeon-by-treatment-group interaction term did not alter the study results.

There was no interaction of diagnosis group and either treatment assignment or hematocrit level measured as a

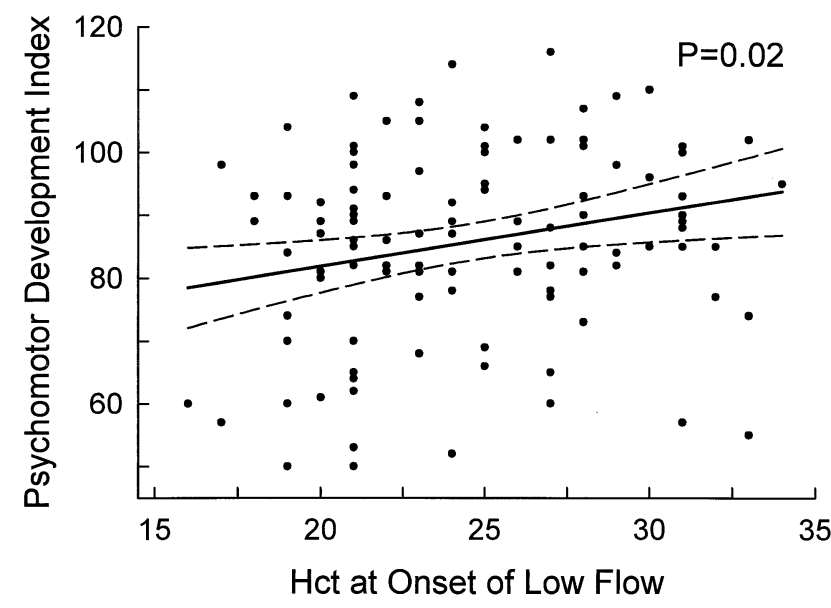

Figure 4. Scatterplot of PDI scores at age 1 year as a function of hematocrit level at the onset of low-flow bypass. The solid line was derived by means of linear regression of the data, and the dashed lines delimit the $95 \%$ confidence interval. Diagnosis was not predictive of this outcome. The linear regression $\boldsymbol{P}$ value shown is for the effect of hematocrit at the onset of low-flow bypass on outcome, with adjustment for diagnostic group.

continuous variable on any outcome measured postoperatively or at age 1 year.

\section{Discussion}

Hemodilution is currently used almost universally for CPB, but the minimum safe hematocrit level remains poorly defined. In our randomized trial we found that children assigned to the lower-hematocrit group had worse perioperative outcomes. In developmental follow-up the lowerhematocrit group had worse scores on the PDI component of the Bayley Scales of Infant Development, as well as a significantly greater proportion with PDI scores more than 2 SDs less than the population mean. The sensitivity of the PDI score to hypoxic-ischemic injury in infancy is likely to reflect the selective vulnerability of cerebral white matter. ${ }^{11}$ Inferences using hematocrit level as a continuous variable were similar to those based on intent-to-treat analyses. Exposure to homologous blood transfusion was the same for both groups.

Studies in animal models of hemodilution during CPB have shown conflicting results. In a canine model systemic oxygen consumption was maintained on $\mathrm{CPB}$ until the hematocrit level was diluted to less than $20 \%,{ }^{12}$ but other studies ${ }^{13,14}$ reported that a critical hematocrit level of $9 \%$ to $14 \%$ maintains adequate oxygen delivery during normothermic CPB. In piglets hemodilution to a hematocrit level of $10 \%$ during hypothermic CPB caused inadequate oxygen delivery during early cooling, and a higher hematocrit level was associated with improved cerebral recovery after deep hypothermic circulatory arrest. ${ }^{3}$ In addition, intravital mi- 
TABLE 3. Scores on developmental tests according to treatment group

\begin{tabular}{|c|c|c|c|}
\hline Test & $\begin{array}{c}\text { Lower hematocrit } \\
\text { level }(n=59) \\
\text { mean } \pm \text { SD }\end{array}$ & $\begin{array}{l}\text { Higher hematocrit } \\
\text { level }(n=53) \\
\text { mean } \pm \text { SD }\end{array}$ & $\begin{array}{c}P \\
\text { value }^{*}\end{array}$ \\
\hline $\begin{array}{l}\text { Psychomotor } \\
\text { Development Index }\end{array}$ & $81.9 \pm 15.7$ & $89.7 \pm 14.7$ & .008 \\
\hline $\begin{array}{l}\text { Mental Development } \\
\text { Index }\end{array}$ & $92.1 \pm 14.5$ & $94.4 \pm 11.0$ & .36 \\
\hline $\begin{array}{l}\text { Psychomotor } \\
\text { Development } \\
\text { Index, no. with low } \\
\text { score/total no. (\%) }\end{array}$ & & & \\
\hline $\begin{array}{l}\leq 85 \\
\leq 70\end{array}$ & $\begin{array}{l}30 / 56(54) \\
16 / 56(29)\end{array}$ & $\begin{array}{c}22 / 53(42) \\
5 / 53(9)\end{array}$ & $\begin{array}{l}.18 \\
.01\end{array}$ \\
\hline $\begin{array}{l}\text { Mental Development } \\
\text { Index, no. with low } \\
\text { score/total no. (\%) }\end{array}$ & & & \\
\hline $\begin{array}{l}\leq 85 \\
\leq 70\end{array}$ & $\begin{array}{c}18 / 59(31) \\
4 / 59(7)\end{array}$ & $\begin{array}{l}6 / 53(11) \\
2 / 53(4)\end{array}$ & $\begin{array}{l}.02 \\
.68\end{array}$ \\
\hline
\end{tabular}

${ }^{*} P$ values are for differences between treatment groups, with adjustment for diagnosis. $P$ values were determined by means of linear regression for continuous outcome variables and stratified exact tests for dichotomous outcome variables.

croscopy in a piglet model ${ }^{15}$ demonstrated that a higher hematocrit level during cooling does not impair cerebral microcirculation.

Several studies in adults undergoing cardiac surgery have suggested that low hematocrit values are associated with worse neurologic outcome, ${ }^{16,17}$ whereas others have found no effect. ${ }^{18,19}$ Newman and colleagues ${ }^{1}$ recently reported an incidence of cognitive decline of 53\% at hospital discharge and $42 \%$ at 5 years but did not examine whether the lowest hematocrit level on $\mathrm{CPB}$ was a risk factor. Similarly, previous pediatric studies have not examined hemodilution as a potential cause of adverse neurocognitive outcome after CPB. In a randomized trial of bypass strategies in children, Kurth and associates ${ }^{20}$ found that cerebrovascular oxygen extraction diminished postoperatively in the group randomized to hypothermic low-hematocrit bypass; however, postoperative neurocognitive function was not assessed.

We found decreased cardiac index and higher serum lactate levels early postoperatively among those with lower hematocrit levels on CPB. Although earlier small studies suggested a wide range of tolerable hematocrit levels, ${ }^{21,22} 2$ recent large studies in adults have supported the hypothesis that lower hematocrit levels during CPB are associated with adverse hemodynamic outcome. ${ }^{23,24}$ The association of low cardiac output with hemodilution might be explained by reduced endocardial blood flow, ${ }^{25}$ thereby decreasing coronary perfusion and myocardial oxygen delivery. In addition, reduced hemodilution could preserve higher serum
TABLE 4. Neurologic abnormalities according to treatment group

\begin{tabular}{|c|c|c|c|}
\hline Variable & $\begin{array}{l}\text { Lower hematocrit } \\
\text { level ( } \mathrm{n}=55) \text {, no. } \\
\text { with abnormality/ } \\
\text { total no. }(\%)\end{array}$ & $\begin{array}{l}\text { Higher hematocrit } \\
\text { level (n = 48), no. } \\
\text { with abnormality/ } \\
\text { total no. }(\%)\end{array}$ & $\begin{array}{c}P \\
\text { value }^{*}\end{array}$ \\
\hline $\begin{array}{l}\text { Overall abnormal } \\
\text { examination result }\end{array}$ & $33 / 55(60)$ & $28 / 48(58)$ & .84 \\
\hline Head circumference & & & .62 \\
\hline Microcephaly† & $3 / 55(5)$ & $0 / 48$ & \\
\hline Macrocephaly $\ddagger$ & $0 / 55$ & $1 / 48(2)$ & \\
\hline $\begin{array}{l}\text { Special senses (visual } \\
\text { or auditory) }\end{array}$ & $2 / 54(4)$ & $2 / 48(4)$ & 1.00 \\
\hline $\begin{array}{l}\text { Cranial nerves } \\
\text { (oculomotor, facial } \\
\text { oromotor function) }\end{array}$ & $23 / 54(43)$ & $18 / 46(39)$ & .84 \\
\hline $\begin{array}{l}\text { Motor function } \\
\text { (strength, tone, } \\
\text { reflexes) }\end{array}$ & $18 / 55(33)$ & $14 / 47(30)$ & .83 \\
\hline \multicolumn{4}{|c|}{$\begin{array}{l}\text { *P values, determined by stratified exact tests, are for differences between } \\
\text { treatment groups with adjustment for diagnosis group. } \\
\text { †Microcephaly is defined as a head circumference less than } 2 \text { SDs below } \\
\text { the mean for age. } \\
\text { ¥Macrocephaly is defined as a head circuference greater than } 2 \text { SDs } \\
\text { above the mean for age. }\end{array}$} \\
\hline
\end{tabular}

oncotic pressure, improving microcirculatory flow and decreasing myocardial edema.

Our data should be viewed in light of certain limitations. Infant neurocognitive tests have good concurrent validity but limited predictive validity in the normal population ${ }^{26}$; however, the predictive validity of the Bayley Scales tends to be considerably higher in samples of at-risk infants. ${ }^{27}$ The relative deficits of children assigned to the lowerhematocrit group were most prominent in motor function, but assessments at older ages might reveal treatment effects in other domains, such as language or visual-motor integration, that are not easily tested in very young children. Children with congenital heart disease might have multiple risk factors for neurologic impairment. To determine the effects of the 2 hemodilution strategies on development using the smallest possible number of subjects, we studied a patient population in whom potential competing risk factors (eg, other anomalies and low birth weight) were minimal at a single center. Finally, assignment to the higherhematocrit strategy provided better outcomes over a range of perfusion variables, suggesting that our findings can likely be generalized. However, we cannot exclude the possibility that differences in intraoperative conduct at other institutions could influence the magnitude of effect of hematocrit levels on postoperative hemodynamic or developmental status. Finally, although hemodilution to $20 \%$ produced outcomes inferior to those at $25 \%$ and greater, we could not determine a specific target hematocrit level of greater than $25 \%$ that was optimal. 
In summary, hemodilution to a hematocrit level currently in wide use and thought to be safe during hypothermic $\mathrm{CPB}^{28}$ is associated with adverse perioperative and developmental outcomes in infants. Indeed, the magnitude of this effect on outcomes at age 1 year (approximately $0.5 \mathrm{SD}$ ) is considerably greater than that associated with low-level lead poisoning ${ }^{29}$ and approximately the same as that associated with very low birth weight $(<1500 \mathrm{~g}) \cdot{ }^{30}$ Use of a higher hematocrit level during hypothermic CPB was not associated with greater use of blood products. Future randomized studies are needed to refine the optimum hematocrit level during infant cardiac surgery and to investigate whether hemodilution contributes to the cognitive decline observed in adults after CPB.

We thank members of our Data and Safety Monitoring Board: Welton Gersony, MD (Chairman), Nathan J. Blum, MD, Erle Austin, MD, Sally A. Hunsberger, PhD, John P. Lantos, MD, and Eli Mizrahi, MD; Gail Pearson, MD, ScD; our perfusionists: Willis G. Gieser, CCP, Robert A. LaPierre, BS, CCP, Robert J. Howe, BS, CCP, Gregory S. Matte, CCP, and William L. Regan; Drs David Bichell and Brian Duncan for enrollment of patients; our nursing staff in the Cardiac Intensive Care Unit for assistance with adherence to the protocol; families and children in the cohort for their time and effort; Ludmila Kyn for database and statistical programming; Donna Donati, Donna Duva, and Lisa-Jean Buckley for data management; and Kathleen Alexander for project coordination.

\section{References}

1. Newman MF, Kirchner JL, Phillips-Bute B, et al. Longitudinal assessment of neurocognitive function after coronary-artery bypass surgery. N Engl J Med. 2001;344:395-402.

2. Sylivris S, Levi C, Matalanis G, et al. Pattern and significance of cerebral microemboli during coronary artery bypass grafting. Ann Thorac Surg. 1998;66(5):1674-8.

3. Shin'oka T, Shum-Tim D, Jonas RA, et al. Higher hematocrit improves cerebral outcome after deep hypothermic circulatory arrest. J Thorac Cardiovasc Surg. 1996;112:1610-20.

4. Neptune WB, Bougas JA, Panico FG. Open heart surgery without the need for donor blood priming in the pump oxygenator. $N$ Engl J Med. 1960;263:111-5.

5. Cooper JR, Slogoff S. Hemodilution and priming solutions for cardiopulmonary bypass. In: Gravlee GP, Davis RF, Utley JR, editors. Cardiopulmonary bypass principles and practice. Baltimore, Md: Williams and Wilkins; 1993. p. 124-37.

6. Gold JP, Charlson ME, Williams-Russo P, et al. Improvement of outcomes after coronary artery bypass. A randomized trial comparing intraoperative high versus low mean arterial pressure. J Thorac Cardiovasc Surg. 1995;110(5):1302-11.

7. Sungurtekin H, Cook DJ, Orszulak TA, Daly RC, Mullany CJ. Cerebral response to hemodilution during hypothermic cardiopulmonary bypass in adults. Anesth Analg. 1999;89(5):1078-83.

8. Cooper JR Jr. Perioperative considerations in Jehovah's Witnesses. Int Anesthesiol Clin. 1990;28:210-5.

9. Hammon JW, Stump DA, Butterworth J, Moody D. Approaches to reduce neurologic complications during cardiac surgery. Semin Thorac Cardiovasc Surg. 2001;13:184-91.

10. Bayley N. Bayley Scales of Infant Development. 2nd ed. San Antonio, [TX]: Pyschol Corp; 1993.

11. Volpe J. Hypoxic ischemic encephalopathy: biochemical and physiological aspects. In: Volpe J, editor. Neurology of the newborn. Philadelphia: W.B. Saunders; 2001. p. 217-76.
12. Kawashima Y, Yamamoto Z, Manabe H. Safe limits of hemodilution in cardiopulmonary bypass. Surgery. 1974;76:391-7.

13. Liam BL, Plochl W, Cook DJ, Orszulak TA, Daly RC. Hemodilution and whole body oxygen balance during normothermic cardiopulmonary bypass in dogs. J Thorac Cardiovasc Surg. 1998;115:1203-8.

14. Cook DJ, Orszulak TA, Daly RC, MacVeigh I. Minimum hematocrit for normothermic cardiopulmonary bypass in dogs. Circulation. 1997; 96(suppl):II200-4.

15. Duebener LF, Sakamoto T, Hatsuoka S, et al. Effects of hematocrit on cerebral microcirculation and tissue oxygenation during deep hypothermic bypass. Circulation. 2001;104(suppl):I260-4.

16. Cook DJ, Oliver WC Jr, Orszulak TA, Daly RC, Bryce RD. Cardiopulmonary bypass temperature, hematocrit, and cerebral oxygen delivery in humans. Ann Thorac Surg. 1995;60:1671-7.

17. Savageau JA, Stanton BA, Jenkins CD. Neuropsychological dysfunction following elective cardiac operation. $J$ Thorac Cardiovasc Surg. 1982;84:585-94.

18. Townes B, Bashein G, Hornbein T, et al. Neurobehavioral outcomes in cardiac operations. A prospective controlled study. J Thorac Cardiovasc Surg. 1989;98:774-82.

19. van Wermeskerken JK, Lardenoye JWH, Hill SE, et al. Intraoperative physiologic variables and outcome in cardiac surgery: Part II. Neurologic outcomes. Ann Thorac Surg. 2000;69:1077-83.

20. Kurth CD, Steven JM, Nicolson SC, Jacobs ML. Cerebral oxygenation during cardiopulmonary bypass in children. $J$ Thorac Cardiovasc Surg. 1997;113:71-9.

21. Niinikoski J, Laaksonen V, Meretoja O, Jalonen J, Inberg MV. Oxygen transport to tissue under normovolemic moderate and extreme hemodilution during coronary bypass operation. Ann Thorac Surg. 1981;31:134-43.

22. Jones JW, Rawitscher RE, McLean TR, Beall AC, Thornby JI. Benefit from combining blood conservation measures in cardiac surgery. Ann Thorac Surg. 1991;41:541-6.

23. Fang WC, Helm RE, Krieger KH, et al. Impact of minimum hematocrit during cardiopulmonary bypass on mortality in patients undergoing coronary artery surgery. Circulation. 1997;96(suppl):II194-9.

24. DeFoe GR, Ross CS, Olmstead EM, et al. Lowest hematocrit on bypass and adverse outcomes associated with coronary artery bypass grafting. Ann Thorac Surg. 2001;71:769-76.

25. Kleinman LH, Yarbrough JW, Symmonds JB, Wechsler AS. Pressureflow characteristics of the coronary collateral circulation during cardiopulmonary bypass. Effects of hemodilution. J Thorac Cardiovasc Surg. 1978;75(1):17-27.

26. Ross G. Some thoughts on the value of infant tests for assessing and predicting mental ability. J Dev Behav Pediatr. 1989;10:44-7.

27. Kopp C, McCall R. Predicting later mental performance for normal, at risk, and handicapped infants. In: Baltes P, Brim O, editors. Life-span development and behavior. New York: Academic Press; 1982. p. 33.

28. Kirklin JW. Hypothermia, circulatory arrest, and cardiopulmonary bypass. In: Kirklin JW, Barratt-Boyes BG, editors. Cardiac surgery. New York: Churchill Livingstone; 1993. p. 78.

29. Bellinger DC. Interpreting the literature on lead and child development: the neglected role of the "experimental system." Neurotoxicol Teratol. 1995;17:201-12.

30. Wolke D. Psychological development of prematurely born children. Arch Dis Child. 1998;78:567-70.

\section{Discussion}

Dr William A. Baumgartner (Baltimore, Md). I would like to congratulate Dr Jonas and his colleagues on an extremely wellpresented randomized prospective study of the influence of hemodilution in infants undergoing hypothermic $\mathrm{CPB}$, the results of which could have significant influences on the refinement of CPB in the specialty of congenital heart surgery, as well as potentially in its application to adults undergoing CPB.

The authors have demonstrated the negative effect of a lower hematocrit level on perioperative outcomes, including a lower cardiac index, a higher serum lactate level, and a greater increase 
in total body water. Of significant importance is the demonstration that 1-year neurologic evaluation demonstrated significantly worse scores in patients in whom hematocrit levels averaged $21.5 \%$ versus $27.8 \%$.

In addition to the neurologic decline associated with infants undergoing CPB with a low hematocrit level, the authors demonstrated worse perioperative outcomes. These pediatric findings do have a corollary within adult cardiac surgical populations. In a recent article from the Northern New England Cardiovascular Disease Study Group, DeFoe and associates performed a retrospective review of a consecutive series of 6980 patients undergoing isolated coronary artery bypass graft surgery. After adjustment for preoperative differences in patient and disease characteristics, the lowest hematocrit level during CPB was significantly associated with increased risk of in-hospital mortality and postoperative placement of an intra-aortic balloon pump.

The other major adult inference in this particular study is based on their study populations of infants. Microembolism, as you heard from Dr Jonas, is thought to be the most plausible explanation for neurocognitive decline seen in adults. Infants, as he mentioned, are generally free of atherosclerosis and therefore would be at significantly less risk for microembolism, suggesting that the neurologic decline seen in adults might be significantly influenced by other nonatherosclerotic variables, including a lower hematocrit level.

This work from the Children's Hospital in Boston is a classic translational study built on their experimental research work. These results have direct clinical application to children undergoing hypothermic $\mathrm{CPB}$ and will stimulate those of us interested in neurocognitive decline in adults to examine what would appear to be a significant $\mathrm{CPB}$ variable.

I have a couple of questions for Dr Jonas. Because neurologic sequelae can be attributed to many factors, including the time of both cooling and rewarming, especially when deep hypothermic circulatory arrest is used, would you please comment on the technique used in these infant operations?

My second question concerns the children who did not return for their neurologic testing. Of the 146 children who were alive at 1 year, 33 were not evaluated for a variety of reasons. Of this group of patients, how were they divided on the basis of the 2 hematocrit groups, and did you see any significant differences in perioperative outcome in this select cohort of children?

In summary, the authors' results demonstrate for the first time that neurocognitive decline in infants is associated with lower hematocrit levels during hypothermic $\mathrm{CPB}$ and suggest that this might be a significant variable in the decline of neurocognitive outcomes in adults.

Dr Jonas. Thank you, Dr Baumgartner. Our group in Boston has admired for many years the outstanding work that you and your group have undertaken at Hopkins looking at cerebral protection in this same area.

In answer to your question regarding our specific technique of hypothermic CPB in infants, there were 5 surgeons who were part of this particular trial. We did use different methods of venous cannulation, and there were no specifications as to which temperature one should cool to, for example. However, patients were randomized according to surgeon, and there was no influence of surgeon on the hematocrit outcome.
My own technique for hypothermic bypass for patients undergoing an arterial switch procedure or repair of tetralogy is to use a single venous cannula and to rely on competence of the tricuspid valve to avoid air entrainment. In the past we used to use a very cold prime in going on to bypass. We now believe that that is a mistake. We think that it is important to begin with a prime that is relatively warm, at least $30^{\circ} \mathrm{C}$ and possibly warmer. This is because of the effect that hypothermia has in shifting oxyhemoglobin dissociation to the left, which I think is one of the fundamental problems that we are seeing here, that it is the combination of hypothermia plus the alkaline $\mathrm{pH}$ that results if one uses the alpha-stat strategy in combination with hemodilution that critically limits oxygen delivery in the early phase of cooling before circulatory arrest or before reduced-flow bypass or during just regular bypass itself. Therefore the $\mathrm{pH}$-stat strategy, we believe, is also a very important part of the technique and is now routinely used at Children's Hospital in Boston. Incidentally, we have noted that in a recent survey the $\mathrm{pH}$-stat strategy is now used in approximately $60 \%$ of programs doing pediatric cardiac surgery. I cool in this fashion over a period generally in the region of 15 to 20 minutes. We think that the old method of very rapid cooling of perhaps 5 to 10 minutes, which is the way we used to do it 15 or 20 years ago, is no longer appropriate, although it is difficult to put a specific number on cooling time if one is going to deep hypothermia, for which we generally use a rectal temperature of less than $18^{\circ} \mathrm{C}$, which usually corresponds to a tympanic membrane temperature of $15^{\circ} \mathrm{C}$.

If we use reduced flow bypass at deep hypothermia, we would go to a flow rate of $50 \mathrm{~mL} \cdot \mathrm{kg}^{-1} \cdot \mathrm{min}^{-1}$. In an average-size neonate that corresponds to a flow index of about $0.75 \mathrm{~L} \cdot \min ^{-1}$ $\cdot \mathrm{m}^{-2}$

We do not believe that the rewarming phase is as critical as the cooling phase. All of our laboratory studies and all of our clinical studies - this is our third large prospective trial- have pointed at the cooling phase as being the critical time when injury occurs. This is the time when the brain is still warm and has a high metabolic rate, and this is when you suddenly limit oxygen delivery through the factors that I mentioned. But generally if rewarming from deep hypothermia, we would rewarm over approximately 30 minutes back to a rectal temperature of $35^{\circ} \mathrm{C}$. We do think that excessive rewarming is a mistake. And the temperature in the first 24 hours postoperatively should also be very carefully controlled. I think that the fever that one sees from bypass or from any other cause can be an important contributor to exacerbating the neurologic injury that might otherwise result from the factors that we have talked about to this point.

Regarding your second question, there were 146 children who were alive at 1 year, and of these, we actually did not invite 20 to return. This was because 12 of them lived overseas, 3 of them had parents who could not speak English, and we did not have travel funds available for 4 patients. We were paying for the majority of these patients to travel some distance. Of the 126 families who were invited to return, 4 declined participation, 3 were lost to follow-up, and 2 cancelled their travel, which was planned immediately after September 11th. Four families declined in-person evaluation but completed questionnaires.

The return rates for the 2 randomization groups were similar, and we did undertake careful comparisons of the 113 patients who 
returned with the 34 patients who did not and found no statistically significant differences in treatment assignment or in any perioperative outcome. However, the children who returned were more likely to be white and to have higher maternal or paternal education, and therefore we subsequently adjusted for race and parental education in analysis of the 1-year follow-up data and did not find that this made any appreciable difference.

Again, I should emphasize that the majority of patients who did not come back were actually not invited to come back and were not self-selected, and therefore hopefully we did not introduce bias in this way.

In summary, we agree with you that patient selection is an important issue that needs to be carefully examined in follow-up studies of developmental outcome. However, we believe it is unlikely that patient selection had a significant effect on the results of our trial.

Dr Vaughn A. Starnes (Los Angeles, Calif). I enjoyed your article very much, and again, it is a major contribution to making bypass in children safe.

When it comes to regional distribution of blood flow, and looking at your groups, particularly in the transposition group, where we can have major collaterals and flow-distribution issues, was that controlled for just with intergroup numbers being the same of transposing each of the group or equalization of that?

Dr Jonas. We did not enroll patients who had TOF with macroscopic collateral vessels, and I am not aware of any patients in the series who had collaterals of a sufficient size, for example, to warrant subsequent coil embolization. But we did not specifically attempt to measure collateral return coming through diffuse collateralization. The majority of these patients are quite young, so that hopefully there would not have been development of collaterals over time resulting from chronic cyanosis.

We do think that collaterals are particularly important in those patients who have macroscopic collaterals. It was those sort of patients in whom we had an epidemic of choreoathetosis in the mid-1980s, when we shifted to the alpha-stat strategy. Therefore I think the $\mathrm{pH}$ strategy is particularly important in patients who have large collaterals, and I think the hemodilution effect would likely be magnified in those patients, but we did not specifically measure that or look for that.

Dr Charles D. Fraser, Jr (Houston, Tex). I was wondering if you thought in an individual patient that an ideal hematocrit level would be able to be predicted on the basis of intraoperative variables? In other words, how do you practically decide what would be the ideal hematocrit level during bypass? Also, could you just speculate on how a lower hematocrit level during CPB negatively affects the cardiac index in the postoperative period?

Dr Jonas. If I can take the second question first, in looking through the literature I discovered a very interesting article by our current editor of the Journal. Dr Wechsler has looked at the question of myocardial protection related to hematocrit level. I do not know whether Dr Wechsler would like to comment, but he looked at distribution of blood flow and found that there was reduced flow to the subendocardium with hemodilution in a situation in which there were coronary stenoses in an animal model. I think it is distribution away from watershed areas that is probably important in terms of the cerebral protection in adults. Whether and how that has an effect in children who do not have cerebral or carotid stenoses is unclear to me. This was a surprise finding of the study. We certainly had not hypothesized that hematocrit level would have an influence on myocardial protection.

I would suggest that studies that use measurement of postoperative cardiac output over the first 24 hours are using a particularly effective tool to measure myocardial protection. It is interesting how rarely postoperative cardiac output has been used over the years. Therefore I do not have any further speculation other than there is some evidence of redistribution of flow away from the subendocardium with anemia.

Regarding the ideal hematocrit level for an individual patient, the unknown question that remains at this point is this: if $27 \%$ is better than $21 \%$, is $35 \%$ better than $27 \%$ ? In fact, we are currently enrolling patients in a trial in which we are randomizing patients between $35 \%$ and $25 \%$. There is clearly an interaction between factors, such as the flow rate and the $\mathrm{pH}$, and the ideal hematocrit level. In our laboratory model right now we are examining exactly that question because the fact is that up until now we have really flown blind; it is like flying an aircraft in fog without instruments. We choose temperatures, flow rates, hematocrit levels, and $\mathrm{pH}$ without any real understanding as to how effectively we are delivering oxygen to cerebral neurons, but hopefully within another 2 to 3 years we will have more information regarding ideal hematocrit levels for the specific conditions of temperature, flow rate, and $\mathrm{pH}$ for an individual patient.

Dr Soon J. Park (Minneapolis, Minn). Dr Jonas, this is a wonderful study. I have a question. In the adult population, at least in our institution, we are using systemic venous oxygen saturation $\left(\mathrm{SvO}_{2}\right)$ monitoring extensively during the period of cooling and rewarming. Have you used these data in this children's study, and then, would you modify your practice on the basis of $\mathrm{SvO}_{2}$ ? For example, patients with a low hematocrit level, did they have substantially lower $\mathrm{SvO}_{2}$ values during the phase of operation compared with children in the higher-hematocrit group?

Dr Jonas. I think you raise a very important point. When I say we have flown blind without instruments, I think we have been seriously misled by $\mathrm{SvO}_{2}$. That has really, in a sense, been our gold standard, and I firmly believe that under conditions of hypothermia and with an alkaline $\mathrm{pH}$ resulting from use of the alpha-stat strategy that $\mathrm{SvO}_{2}$ can be extremely misleading. I am sure you have noted that immediately on commencing rewarming you see a decrease in $\mathrm{SvO}_{2}$. Why does that happen? The brain and the body have not yet had an opportunity to rewarm and to increase their metabolic rate and oxygen requirement, and yet there is an almost immediate decrease in venous oxygen saturation. I would suggest that this phenomenon demonstrates the fact that there has been inadequate oxygen delivery related to the effects I have been talking about and suggest that an oxygen debt has been incurred.

Therefore when you and me and our perfusionists are reassured by seeing an $\mathrm{SvO}_{2}$ of $95 \%$ or $100 \%$, I think we are being falsely reassured. I think in fact that there might be an oxygen debt being incurred in spite of high venous oxygen saturations. In this study we did not place monitoring catheters to monitor $\mathrm{SvO}_{2}$ postoperatively, but we did, of course, use continuous on-line monitoring of $\mathrm{SvO}_{2}$ during bypass. 